\title{
STUDYING THE GROWTH OF CANADA'S FORESTS
}

\author{
By W. M. Robertson, Dominion Forest Service
}

$\mathrm{A}^{\infty}$

CCORDING to the best available data, about one third of Canada's

area, nearly 1,200,000 square miles, may be classed as forest lands.

About one quarter of the timbered land is unprofitable or inaccessible at the present time, while one half is young growth not yet ready for the axe; the remainder, some 300,000 square miles, carries merchantable timber. It is further estimated that on the average 3,800 square miles are being cut over, and 3,500 square miles burned over annually. To reforest these lands satisfactorily by planting would probably cost Canada seventy million dollars per year. Fortunately nature, if given a chance, can assume practically all of this load. Natural reproduction, although perhaps not always of the most desirable species, is reclaiming a goodly percentage of the cut-over and burned-over lands. It cannot be denied, however, that Canada's timber situation is uncertain, perhaps serious. It is a certainty that a hiatus will occur, in some regions at least, between the time of exhaustion of the present supply and the merchantability of the new supply.

Forest authorities realize that annual depletion,--by which is meant total wastage through utilization and losses from all causes,-is in excess of annual growth. In other words, the capital stock is being reduced. If our forest industries are to be permanent, the proper balance must be maintained, not only in the country as a whole, but in each section of timbered area. It is highly important, therefore, to have more reliable information relative not only to the present supply and its distribution, but to the rate at which these supplies are increasing in volume and to the amount of second growth or potential forests. It is important to know, too, whether they may be expected to mature at such dates as will avoid a period of famine. A careful study must be made of the cut-over and burned-over lands to determine whether sufficient regeneration of the desirable species to supply future needs is following the removal or destruction of the former stands.

Within the past few years both Sweden and Finland have completed a country-wide survey of their timber resources and growth-rate, on the basis of which they are intelligently managing their forests to provide the largest possible continuous supply in perpetuity.

As you know, at a conference of the Federal and Provincial authorities held in June, 1929, a similar Canada-wide survey was launched, the Provincial Services agreeing to undertake as a co-operative project the collection of data for an inventory of the present stand. The Forest Service, Dept. of the In- 
terior, was constituted as the clearing house for the correlation and assembly of the information secured, as well as conducting the inventory in the prairie provinces. In addition, too, the Research Division of the Dominion Forest Service was assigned the task of determining the growth-rates applicable to the general inventory, a project of no mean magnitude, encompassed by many difficulties.

Nevertheless, at the close of the second field season such progress has been made as would indicate that the objective will be attained within the fiveyear period estimated as the time-limit at the Conference.

At this point it might be well to enunciate the problem in hand. In undertaking this rate of growth survey covering the timbered lands of Canada, it is proposed to determine the current annual increment based on the growth of the past ten years, both in percentage and in cubic volume for each species, age-class, and subtype for the average stand in each broad timberbelt. Such information involves not only a measurement of increment, but a determination of the average stand. At the same time the fullest possible information is being collected relative to reproduction, mortality, groundcover, soils, and history of cutting, fires, and other influencing agencies.

Assuming that the broad inventory survey will furnish information as to the average stocking and total areas of each important subtype, there should be little difficulty in linking the two surveys and thereby determining not only Canada's timber capital and interest, but also its distribution by provinces and belts, by subtypes, age-classes, and species.

In a project of such scope, it is beyond the realm of possibility that sufficient information can be collected upon which to base growth-rate upon any restricted area. It is equally impossible to predict what future growth may be, even for a period of ten years, on such extensive areas as are necessarily considered. It will be a comparatively simple matter, however, to collect the necessary additional information to determine not only the current annual growth but also to predict the growth for a ten-year period for any given locality, as has already been done for the Nashwaak drainage area in the province of New Brunswick.

Before launching upon a project of such magnitude careful study was made of the work of other countries, and extensive discussions were held by correspondence with leading authorities in Canada and abroad before the present methods were accepted. Careful balancing between intensity of survey and time, personnel, and funds available was demanded, and although increased intensity at certain points was found necessary at the end of the first season, it would seem that a satisfactory balance has now been struck.

The purpose of the investigation determined, the next logical step with this, as with any other survey, is an examination of existing data, having in mind orientation, subdivision, and general planning of the field operations. 
As a preliminary subdivision that of Dr. Fernow and Mr. Craig, dividing Canada into three broad regions, and these again into series of timber belts, based on the general occurrence of species found thereon, was accepted, sub. ject to correction from time to time as more accurate information becomes available. Modifications have been made in the designation of belts in Ontario to conform to the subdivisions as found in the stock-taking surveys of that province; and some changes in the belt boundaries in Quebec recommended by the provincial Service have influenced the location of future field activities.

Within each belt a series of "areas" were tentatively selected from a study of existing maps and survey reports; and confirmed or revised in consultation with the interested provincial authorities. Each area represents a section of country that can be covered by one field party in a single field season.

Within each area a series of sixteen blocks, separated by intervals of ten or more miles, is selected, each block representing one week's work for the field party of eight men. In selecting the blocks the provincial authorities are again consulted; and whenever it can be arranged, the final selection is made from an actual inspection of the ground from the air. An entire area can be minutely inspected from the air in the course of a few hours, thereby eliminating false moves and useless loss of time for the entire field party.

In 1929 the blocks were twenty-five square miles in area; on each of them fifty sample plots of two square chains, spaced at intervals of forty chains, were established. It was found, however, that blocks of this size were somewhat unsatisfactory, since it required the full time of the crew for a day to work the five plots from the centre of the block to its outer edge and consequently it was not possible to establish plots on the return to the centre baseline. Therefore, the sides of the blocks have been reduced to $21 / 2$ miles, the interval between plots to twenty chains, the size of plots to one square chain, and the number of plots required per block has been doubled to one hundred. Under ordinary circumstances each party of two three-man crews has little difficulty in establishing twenty or twenty-four plots per day, and at the end of the day the party is back at the base-line of commencement, usually not more than a mile from camp.

In running the line between plots the chief of the crew records every change of subtype or age-class encountered. Plots are carefully surveyed by chain and compass and the boundaries marked by counter twine to ensure accuracy of the tally. The records taken on each plot may be enumerated as follows:-

1. A diameter tally of all living trees one inch D.B.H. and over, and of all dead trees which are considered to have died within the past ten years. 
2. Borings are made on two sides of from two to ten trees and the growth for the past twenty years recorded.

3. The same trees are measured for height by Abney hand-level.

4. A tally is made of the reproduction found on a square-rod plot, the seedlings being classified by species, age, and height.

5. A detailed description of the history, soil, and ground vegetation of the plot is taken.

In classifying these records, as many as twelve sub-types and six age-classes are recognized, and hence the 1600 sample plots are not an excessive number upon which to base the requisite representative stand tables for each area. Indeed, it is very probable that some of the minor subtypes and age-classes will not be amply represented until the data for all areas within each belt are combined, consequently annual interim reports will not be complete within themselves.

Possibly the most pronounced weakness in the single-examination survey of this nature is the basis of calculating mortality. While in some instancesfor example, on an area that has been cut over recently-it may be possible to determine with a fair degree of confidence the trees that have died since the logging, even under most favourable circumstances the estimate of mortality within a given period is a matter of conjecture. For more reliable information dependence must be placed upon permanent sample-plot records or at least upon repeated measurements of the same area. However, from what information is already available, it seems apparent that the natural stem-number decrease, aside from wind or insect havoc, is remarkably low in cut-over and understocked stands.

During 1929 each field-party made over 6000 increment borings,--a goodly number-and yet when these were divided among the 72 divisions, each of which is possibly divided into ten species and each of these species perhaps into fifteen diameter-classes, it becomes apparent that such intensive subdivision was not possible. Consequently, in compiling the 1929 data, ageclass subdivision had to be deferred and left for consideration when combining the several areas within the belt. In order that the records for each area might be more nearly self-sufficient and provide satisfactory growth data for the more important subdivisions and age-classes, one extra man was added to each party his sole duty being the making of increment records. This made it possible to collect 18,000 measurements during the last season.

In analysing the increment borings of the past two years, a somewhat important discovery has been made. In making increment borings the usual practice has been to make but a single boring in each tree (except for intensive work where four borings are taken and averaged), on the assumption that irregularities due to eccentricity of wood accretion will tend to compensate if large numbers of measurements be taken. To investigate this point, 
it was required in 1930 that two borings be made on opposite sides of each tree. The data thus secured have been analysed and the results given in an article by Mr. G. A. Mulloy, appearing in an early issue of the Chronicle are very interesting. It would appear that the first boring on most trees is larger than the second, the reason possibly being that there is a pronounced tendency for the field man to select a clear place on the tree for the first measurement where growth is probably abnormal, and having then no choice for the location of the second measurement, he is forced to take it where growth conditions are less favorable. Be that as it may, it would seem more desirable to bore a fewer number of trees twice than the maximum number once.

In 1929 activities were confined to Eastern Canada with a party in each of the provinces of Nova Scotia, New Brunswick, Quebec, and Ontario. Four more parties were added in 1930, one in Manitoba and Saskatchewan, one in Alberta, and two in British Columbia.

Interim reports have been issued covering the work of 1929 in the provinces of Nova Scotia and New Brunswick. Except for two or three subtypes, the date for the other two provinces were insufficient to warrant the issuing of an interim report. It is expected that reports combining the data of the two seasons will be possible this year.

The province of Nova Scotia, with the exception of Cape Breton Island, has now been covered and, thanks to the co-operation of the Forest Service of New Brunswick, in placing an extra party in the field last year, that province has also been completely sampled. As soon as the data can be compiled, the final report covering the entire province can be undertaken.

Time will not permit of a discussion of the methods adopted in compiling the data, but these are outlined in considerable detail for the guidance of the officers of the Dominion Forest Service, a copy of which outline (Research Note No. 30) may be had upon application to the Director of Forestry, Department of the Interior, Ottawa.

A brief summary of the interim report on rate of growth in New Brunswick may suffice to indicate concretely some of the information that is being obtained by this survey.

The New Brunswick party of 1929 worked that portion of the province southeasterly of a line between Newcastle, Fredericton, and McAdam, establishing sixteen blocks of twenty-five square miles each, taking 800 samples of two square chains each. Although ten of the twelve sub-types were encountered, only three of them, namely (1) balsam-spruce, (2) black spruce, and (3) white birchaspen, were widely represented; for these 238, 152, and 166 plots respectively were measured.

There is a very close correspondence between the representation of subdivisions as mapped along the strips and that determined by the plots; in 
most instances the difference is not greater than one per cent, an indication that the sample plots are truly representative of the area.

Thirty per cent of the area is of the balsam-spruce subtype, two-thirds of which is in the age-classes 21 to 60 years. Black spruce constitutes 19 per cent. one quarter of which is mature timber. In the white birch-aspen subtype, over 80 per cent is less than 40 years old.

Over 70 per cent of the stands are of the intermediate, i.e., the fastest growing, age-classes. As there is less than 20 per cent of material now ready for the axe, there is some danger of a hiatus before any of the wood in the 40 to 60-year class becomes available.

Until some field work was done to determine the number of subdivisions to be encountered, the number of measurements it is possible to obtain and the general dispersion of those measurements, close calculation of the number of borings required cannot be made. Consequently when the data for 1929 were compiled, it was found that there were insufficient measurements to justify age-class as well as subtype subdivision. As already stated, provision was made in the 1930 plans for the taking of necessary additional measurements.

The average acre of balsam-spruce subtype carries 236 trees or nine cords, spruce and balsam fir being about equally represented. The increment is 23 cubic feet per acre per year, which should increase with improvement of the stocking. The mortality in spruce and balsam fir is half a cubic foot per year. (Mortality for the previous ten years, 1909-1919, due to budworm attack, was very heavy, however).

With regeneration of 4,800 balsam fir and spruce seedlings and 600 saplings per acre, there is nothing in the state of reproduction to cause worry. Growth conditions are not quite so satisfactory in the black spruce subtype, though better than anticipated for that site. The average stand consists of 213 trees or six and a half cords, with an increment of sixteen cubic feet per acre per year. There are ample seedlings and saplings to take care of future requirements. In the white birch-aspen subtype there are 256 trees $(50$ per cent of which are conifers) or nine cords of all species producing sixteen cubic feet per acre per year. In this subtype there are 1200 coniferous seedlings and 300 saplings, indicating early conversion to balsam-spruce subtype.

In general, with the exception of the danger of overcutting the stands presently merchantable, the report indicates a very satisfactory condition existent in that portion of the province.

The data relative to the conditions of the forest have not yet been summarized. This information will be presented on the basis of percentage of occurrence in relation to the number of samples examined. By way of illus- 
tration, a preliminary analysis of ninety plots in a white birch aspen-balsamspruce subtype shows that-

Sixty-six per cent of the area originated after fire; twenty-one per cent was logged over lightly, nine per cent. severely; nineteen per cent. was cut within the past ten years, six per cent twenty years ago, and five per cent over forty years ago. Twenty-seven per cent of the area was burned lightly, since the present stand originated, twenty-four per cent severely; sixteen per cent of the plots were burned in the past ten years, twenty-five per cent over forty years ago, forty-nine per cent have not been burned. As is to be expected in this subtype, the windfall has been very light. Over sixty per cent of the soil is loam or sandy loam, twenty-eight per cent. clay; thirty-nine per cent is dry, fifty-eight per cent moist, and only three per cent classified as wet. In a similar manner, the representative ground flora and underbrush will be analysed to be studied as site indicators in accordance with Cajander's theory.

The rate-of-growth survey completed, the question arises as to how the information is to be applied. This calls for an explanation of the general inventory and the method of assembling it. The objective is the reduction of timber estimates, from whatever source obtained, to the simplest possible statement, for which a standard form has been provided. The form is in three sections-land classification, estimate of stand, and depletion. Under land classification provision is made for non-forested land, non-productive forest lands, and productive forest lands. The productive lands are divided into softwood, mixedwood, and hardwood types. The types in turn are given as merchantable or young growth, the latter divided into three age-classes. When the entire returns have been received and summarized, it should be possible to determine the total acreage of any age-class in any type and belt or partial belt, for instance, the acreage of 40 to 60 -year-old softwood type in the New Brunswick section of the Acadian belt.

The rate-of-growth survey provides a stand table, the current annual in. crement, the estimated mortality, the reproduction, and a statement of history, soil, and ground-cover conditions on the average acre in each age-class in each subtype. It also provides a statement of the proportion of each ageclass in each subtype in the softwood, mixedwood, or hardwood types. Hence it is simply a matter of office compilation to link the two surveys.

It is difficult to fully appreciate the possibilities of aerial surveys in conjunction with systematic ground work in a project so extensive. The area of Canada that has already been mapped from the air is rather remarkable. Although much of it has not been timber-typed, it is only a matter of office work, for timber-typing experts and draughtsmen to finish the maps from which the areas of softwood, mixedwood and hardwoods can be read, and to 
which the rate-of-growth data may be applied. By this means a remarkably intensive estimate of the provinces of Nova Scotia and New Brunswick are not beyond the scope of possibility.

The conclusion of the matter is, then, that the rate-of-growth survey, coupled with the inventory survey, should provide a statement of Canada's timber resources, its current growth, the nature of reproduction, and detailed description of the forest lands. Although the estimate is of necessity of a general nature, nevertheless, since each sample is a complete entity, such samples taken for any given minor area may be separated at any time for use in conjunction with contributory information to provide a statement of the local conditions of growth. As already mentioned, statements of this nature have been provided covering the Nashwaak and the Miramichi drainage areas.

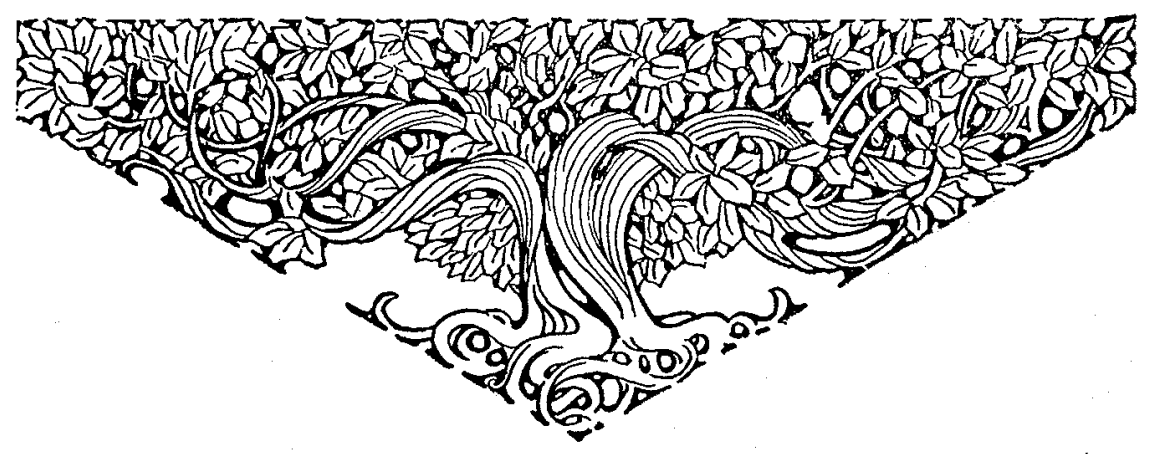

